August -2004

\title{
Interaction and Immediacy in Online Learning
}

\author{
Robert H. Woods, Jr. \\ Spring Arbor University \\ USA
}

Jason D. Baker

Regent University

USA

\begin{abstract}
This article presents the concepts of interaction and immediacy and discusses their theoretical frameworks, implications, and relationship with one another. The authors propose the development of a new conceptual model and recommend additional antecedent research.
\end{abstract}

Keywords: distance education; interpersonal interaction; immediacy; theory; theoretical framework

\section{Introduction}

In the historical progression of distance education from correspondence courses to online learning, opportunities for interpersonal interaction have increased. Early correspondence courses enabled learners and instructors to interact, albeit with a significant time lag between message production and reception. Videoconferencing made it possible for learners and instructors to interact in real-time, and it also facilitated learner to learner interaction, although the required equipment often made this means of distance education too costly for mainstream use. With the emergence of the Internet, particularly email and the World Wide Web (WWW), it became possible to promote high degrees of interaction within a technologically mainstream and costeffective learning environment.

This progression has not only been driven by the myriad of interactive opportunities available in the online environment, but also by the belief that high levels of interaction, particularly those which promote social engagement, can have positive effects on the learning experience. Indeed, numerous studies suggest a positive correlation between relationally supportive online environments and cognitive learning (e.g., Gunawardena, 1995; Wegerif, 1998; Rovai, 2002). Collaboration with faculty and other students can be a strong motivating force for learning (Johnson and Johnson, 1999) and online instructors are frequently encouraged to actively construct a positive social dynamic in parallel with the content delivery (Palloff and Pratt, 1999). Failure to fully consider the relational dynamics in the online setting may produce greater feelings of isolation among distance learners, reduced levels of student satisfaction, poor academic performance, and increased attrition. 
Interaction alone, however, is insufficient to create a positive social dynamic in the online classroom. Although increased interaction among participants may lead to more opportunities for positive social penetration, it may also lead to competition, "flaming," and other forms of negative communication. Research demonstrates that the integration of verbal and non-verbal immediacy communication behaviors lets instructors move from mere interaction to authentic intimacy and interpersonal closeness. In short, an instructor's understanding of interaction and immediacy dynamics will affect the nature and quality of communication in the online learning environment.

Accordingly, this article will highlight the concepts of interaction and immediacy, and discuss their theoretical frameworks, implications, and relationship with one another. The authors will also recommend additional research related to interaction and immediacy, and propose the development of a new conceptual model.

\section{Interaction}

Interaction is at the heart of the online learning experience. One of the foundational theories in distance education is Moore's transactional distance theory, which emerged from his doctoral research into educational programs where the instructor and student were physically separated (Moore and Kearsley, 1996). Transactional distance was a conceived as a function of dialogue, structure, and learner autonomy. Moore postulated that distance was a pedagogical phenomenon, rather than a function of geographic separation, which existed in face-to-face classes as well as distance classes. According to Saba (1999), this was a significant shift in the pedagogical perspective toward distance education, which "moved the discourse on the subject from its Newtonian paradigm and grounded it in a contemporary postmodern science. According to this dynamic (time-sensitive) and systemic (self-organized) view of mediated communication, what is important is communication and construction of knowledge" (para. 6).

Moore (1989) acknowledged that: "Interaction is another important term that carries so many meanings as to be almost useless unless specific sub-meanings can be defined and generally agreed upon" (p. 1). Therefore, he proposed three distinct types of interaction in distance education: learner-content, learner-instructor, and learner-learner. Learner-content interaction is the process in which students examine, consider, and process the course information presented during the educational experience. According to Moore and Kearsley (1996), "Every learner has to construct knowledge through a process of personally accommodating information into previously existing cognitive structures. It is interacting with content that results in these changes in the learner's understanding” (p. 128). Learner-instructor interaction is communication between the instructor and the student in a course. In the case of online learning, such interaction usually occurs via computer-mediated communication and is not strictly limited to instructional communication that occurs during the educational experience, but may include advising, offline communication, and personal dialogue. Finally, learner-learner interaction is communication between two or more students in a course. Such interaction often occurs via asynchronous computer-mediated communication, although it may include other forms of interpersonal and small group communication, online and offline, that occurs during the duration of a course.

This threefold interaction construct has been extended and adapted by subsequent researchers in the area of distance and Web-based learning. Hillman, Willis and Gunawardena (1994) added learner-interface interaction to reflect the growing role of technology in the distance education process. They noted: "When dealing with any tool, it is necessary for the user to interact with the device in a specific way before it will do his or her bidding” (p. 34). They also distinguished 
between learner-interface interaction and the necessary mediation of an interface which occurs in any interaction, by noting that for the technically-challenged learner, the interface itself becomes "an independent force with which the learner must contend" (p. 35). Burnham and Walden (1997) observed interactions within a distance education environment and concluded that learnerenvironment interaction should be added to the model. They defined learner-environment interaction as "a reciprocal action or mutual influence between a learner and the learner's surroundings that either assists or hinders learning” (Findings section, para. 2).

Anderson and Garrison (1998) added teacher-teacher interaction, teacher-content interaction, and content-content interaction to the mix. Teacher-teacher interaction considers the professional development efforts of teachers to engage one another in order to enhance their own pedagogical abilities. Such interaction might occur at conferences, in seminars, or through informal electronic communication (p. 105). Teacher-content interaction, generally viewed as a prerequisite to the distance course, is proposed as another component in the interactive model, because new technologies enable teachers to interact with the content far more easily and creatively than in the past. The authors note: "The opportunity for teachers to interact with the learning content provided by other teachers is increasing dramatically as a result of the WWW" (p. 108). Similarly, they note the growing sophistication of online tools such as databases, search engines, and intelligent agents, and propose content-content interaction. While they note that this is the most embryonic type of interaction, more recent technologies such as blogs, wikis, and content syndication aggregators merely increase the likelihood of content-content interaction actually occurring in a meaningful way.

Although not explicitly defining her model as learner-context interaction, Gibson (1998) drew on ecological systems theory and proposed a model of the distance learner in context. Gibson argues that the distance learner simultaneously engages and interacts with multiple contexts which extend beyond the classroom, such as family, workplace, peer groups, and larger institutions such as government, mass media, and organized religion, extending out to interaction with the larger culture (p. 117).

Dating back to Moore's threefold model of interaction, these approaches have generally emphasized the "who" of interaction at the expense of the "what." In other words, these various models of interaction have largely focused on which entities were interacting rather than clearly defining the nature of interaction itself. Wagner (1994) distinguished between interaction and interactivity, and noted that neither concept had been sufficiently defined. She thus wrote: "Simply stated, interactions are reciprocal events that require at least two objects and two actions. Interactions occur when these objects and events mutually influence one another" (p. 8). In distance education, such interactions are interpersonal and occur within an instructional context. She distinguishes between such human interaction and interactivity, which she describes as a characteristic of the technology itself. "Interactivity may eventually be viewed as a machine attribute, while interaction may be perceived as an outcome of using interactive instructional delivery systems” (p. 26).

Anderson (2003a) revisited the issue of defining interaction in distance education. After surveying a variety of definitions and characteristics of interaction, he returned to the Wagner (1994) definition as a suitable foundation. "Despite concerns about the application of Wagner's simple and broad definition of interaction, her definition does seem to include the essential components and nature of interaction without compromising or restricting the wide range of possible types of interaction” (p. 130). He then proposed a comprehensive model of interaction which included student-teacher, student-student, student-content, teacher-content, teacher- 
teacher, and content-content interaction. In a follow-up effort, Anderson (2003b) confirmed his previous definitional conclusion, but distinguished between "interaction leading to learning in any informal context and those types of interaction that occur in a formal interaction context" (Interaction and Education section, para. 1). He then developed a more sophisticated interaction model of e-learning incorporating all six types of interaction in an expansive framework, which covers a variety of online learning models including independent study, paced collaborative learning, structured learning resources, and communities of inquiry.

\section{Immediacy}

Mehrabian (1967) defined immediacy as the extent to which selected communicative behaviors enhance physical or psychological closeness in interpersonal communication. In other words, immediacy can be understood as "those communication behaviors that reduce perceived distance between people” (Thweatt and McCroskey, 1996, p. 198). Immediacy can have verbal and nonverbal forms. Non-verbal immediacy would therefore be understood as a sense of psychological closeness produced by physical communicative behaviors such as facial expression, eye contact, posture, proximity, and touch. Verbal immediacy would thus be a sense of psychological closeness produced by word selection. For example, the use of the word "we" fosters increased relational closeness and is considered more immediate than the comparable statement "you and I.” Anderson (1979) summarizes the impact of immediacy:

The more immediate a person is, the more likely he/ she is to communicate at close distances, smile, engage in eye contact, use direct body orientations, use overall body movement and gestures, touch others, relax, and be vocally expressive. In other words, we might say that an immediate person is perceived as overtly friendly and warm (p. 545).

Mehrabian (1971) found that such non-verbal behaviors increased sensory stimulation, thus resulting in more intense, affective, and immediate interactions (p. 77). Mehrabian suggested that non-verbal behaviors such as leaning toward another, assuming a position close to another, touching another, facing another, and looking into another's eyes are immediacy producing behaviors. Additional non-verbal immediacy producing behaviors include positive head nods, purposeful gestures, and vocal expressiveness (Andersen, Andersen, and Jensen, 1979). Mehrabian (1971) and later Gorham (1988) described verbal immediacy behaviors as linguistic differences in expression from which feelings of like and dislike are inferred. Asking questions, using humor, addressing individuals by name, initiating discussion, and sharing personal examples are verbal behaviors which produce immediacy and contribute to a sense of psychological closeness.

Although immediacy was originally developed in the interpersonal communication context, it has been frequently used in instructional communication research during the past two decades. With the rapid diffusion of the Internet into a mainstream communication medium, there has been a clear emphasis on the dynamics of interpersonal communication in the online environment. Although not necessarily referencing the immediacy concept by name, there is significant conceptual overlap between examinations of traditional immediacy producing behaviors and discussions of online interpersonal communication dynamics. 


\section{Interaction and Immediacy Intertwined}

Online education environments offer the opportunity for increased interaction - regardless of how many types of interaction are considered - than previous models of distance education. In particular, there has been significant emphasis in the literature about how to promote interpersonal interaction with the tacit understanding that high levels of interaction will produce positive results, particularly results related to social dynamics. Such an emphasis on (and perceived benefits associated with) interpersonal social dynamics is consistent with the constructivist framework, which appears to be dominant in online learning pedagogy. An unstated assumption, however, appears to be that promoting interaction will lead to positive communication behaviors such as instructor immediacy, social presence, and community in the online classroom. Accordingly, much of the literature (particularly best practices texts) integrates the concepts of interaction and immediacy into a seamless presentation extolling the benefits of social interaction.

De Verneil and Berge (2000) noted: "It is important in most Web-based instruction that a designer explicitly includes learning in social context... since the learning process takes place within a social framework" (p. 236). They argued that promoting student interaction through class discussions, are integral to effective online learning. Harasim (1989) examined online courses and drew a similar conclusion about the value of student interaction and discussion. She added: "Knowledge building occurs as students explore issues, examine one another's arguments, agree, disagree, and question positions. Collaboration [learner-learner interaction] contributes to higher order learning through cognitive restructuring or conflict resolution, in which new ways of understanding the material emerge as a result of contact with new or different perspectives" (p. 55) (emphasis added).

Kearsley (2000) declared: "The most important role of the instructor in online classes is to ensure a high degree of interactivity and participation" (p. 78). Parker (1999) similarly highlighted the pedagogical benefits of student interaction, but offered the caveat that while it is a much-needed component of online courses, it is less likely to occur without the careful orchestration by the instructor:

The sentiment of many faculty is to teach the same course offered on campus with the addition of a few more handouts. To those experienced in the art of distance delivery, it is evident that the addition of a few more handouts is not the solution for interactive course design ... The challenge lies in the refocusing of the instruction to embody a component of interaction (p. 16).

Such refocusing might include the use of group projects, running dialogues about complex issues, and by making class discussion a significant part of one's course grade. Parker also observed that the instructor role likely takes different forms throughout the duration of the course. Early in the term, the instructor is likely to lead by example and direct the discussions but, as the weeks progress, the instructor should assume the role of "provocateur" rather than "academician" and produce no more than 20 percent of the class input (p. 16). She also encouraged faculty to incorporate "real life" stories and humor to foster a discussion-friendly climate, recommendations which could be classified as immediacy-producing behaviors, even though they were not labeled as such. This is similar to De Verneil and Berge (2000) who suggest that instructors ask students to post a biography, request active participation, provide feedback to students about their participation level, provide a virtual caf\#233; for socializing purposes, and make synchronous chat rooms available should students want to interact in real-time (p. 236-237). 
Berge (1997) conducted a survey of instructors teaching online at the post-secondary level to better understand the pedagogy of online courses. While no single model of online learning emerged, Berge found that most instructors deliberately fostered a student-centered rather than teacher-centered environment through various instructional methods. "Predominant among these were discussion, collaborative learning activities, and authentic learning activities (i.e., inquiry, problem-based activities, case studies, projects, peer critique and support), and self-reflection” (p. 44). Woods and Ebersole (2003) reported that encouraging student interaction in personal discussion folders contribute to positive faculty/ student relationships, positive relationships among students, a sense of community, and satisfaction with the overall learning experience. In short, such efforts can be used to encourage openness among the students and ideally lead to a high level of student interaction. As interaction increases, particularly interaction of the type which promotes immediacy, opportunities for social penetration abound. These opportunities, in turn, foster a climate of interpersonal interaction that may have positive benefits for interaction in course-related discussion areas.

Although they examined distance education delivered via interactive television, Fulford and Zhang (1993) found that the perception of interaction, rather than a quantitative measure of interaction, was the critical predictor of student satisfaction. "This finding strongly suggests that learner satisfaction may be attributed more to perceived overall interactivity than to individual participation. Instructors teaching thorough interactive TV probably should be more concerned with overall group dynamics” (p. 18). In a similar vein, Clow (1999), Phillips and Peters (1999), Roblyer (1999) and Hacker and Wignall (1997) all concluded that a student's perception of sufficient interaction with instructors and other students is positively correlated with his level of satisfaction with the overall online learning experience. A 'sufficient' level of interaction with faculty generally creates a "sense of personalization and customization of learning" (Boettcher, 1999, p. 43) and helps students overcome feelings of remoteness - perhaps the greatest obstacle to fostering a student's sense of community in online distance learning (Everhart, 1999, p.12). Arbaugh (2000) found that perceived interaction difficulty was negatively correlated with student satisfaction, while perceived instructor emphasis on interaction was positively correlated with student satisfaction. Arbaugh concluded: "It appears that the flexibility of the medium and the ability to develop an interactive course environment play a larger role in determining student satisfaction than the ease or frequency with which the medium can be used” (p. 43).

Gender also appears to influence the online communication dynamics. Women are more likely to seek supportive communication environments (Brunner, 1991; Burnham, 1988; Ryan and Hicks, 1997) and thus are likely to have significantly different expectations when it comes to frequency and nature of communication online. Instructors attempting to enhance interaction must also keep in mind that messages from males engaged in threaded discussions tend to be more certain, confrontational, autonomous, controlling, and abstract than messages from females, which tend to be more empathetic, and cooperative (Blum, 1999). Arbaugh (2000) found that women participated more than men in class discussions and were more collaborative, while the men were more competitive. Herring (2000) found that female students participated more when the instructor actively promoted a civil and focused discourse. In other words, both gender and communication style influenced levels of interactivity and immediacy-producing behaviors, and were more consistent with female online communication than with male communication.

LaRose and Whitten (2000) borrowed from social cognitive theory as a framework to develop a unified construct of interaction and instructional immediacy for Web-based courses. Specifically, they sought to create a model that incorporated not only teacher and student immediacy, but also 
computer immediacy, which they proposed as a result of an ethnographic content analysis of three Web courses. Within this social cognitive framework, they concluded:

There are three possible sources of immediacy in the virtual classrooms of the Web that may create feelings of closeness: 1) the interactions between teacher and students (teacher immediacy); 2) interactions between students (student immediacy); and 3) interactions with the computer system that delivers the course (computer immediacy). Collectively, these sources constitute instructional immediacy. In each case, learning is motivated either through social incentives (e.g., approval for good behavior, expressions of interest in the student) or status incentives that recognize or enhance the status of the learner. The immediacy mechanism is enactive if it results from the interaction between a specific individual learner and one of the other agencies present in the classroom. Immediacy is vicarious if it operates through the observation of other learners as they interact (p. 336).

LaRose and Whitten's three loci of interactions attempt to formalize the relationship between the basic building blocks of interpersonal interaction in the online classroom, while focusing on the resulting social dynamics (e.g., immediacy) which are often antecedent.

\section{Recommendations}

Although the LaRose and Whitten (2000) model more explicitly connects interaction and immediacy than most research, it is sufficiently representative in that it presents interaction as a necessary dynamic within the online classroom, which results in positive social and educational benefits. Unfortunately, such co-mingling of interaction and immediacy insufficiently considers the extent to which immediacy is both a consequence of interaction and a contributor to it, as well as omitting the extent to which interaction can lead to non-immediate results. Accordingly, we recommend revisiting the definitional framework of interaction itself with an eye toward immediacy and other social dynamics.

Wagner's (1994) foundational definition described interaction reciprocal objects and events which influence one another. Such an admittedly broad definition successfully advances beyond a one-way or transmission model of communication into a two-way or dialogic model (Carey, 1989), although the learner-content interaction pushes the boundary as the majority of the interaction is likely to be part of the learner's "internal didactic conversation” (Holmberg, as cited in Moore, 1989, p. 2).

Building on a similar foundation of reciprocal influence, Rafaeli (1988) distinguished between three types of communication sequences: two-way (non-interactive), reactive (quasi-interactive), and fully interactive. According to Rafaeli:

Two-way communication is present as soon as messages flow bilaterally. Reactive settings require, in addition, that later messages refer to (or cohere with) earlier ones. Full interactivity (responsiveness) differs from reaction in the incorporation of reference to the content, nature, form, or just the presence of earlier reference (p. 119). 
This model offers a significant advance to an understanding of interaction as mere reciprocal interaction, but proposes that the nature or content of the communication events distinguish between levels of interactivity.

Although considering human-computer interaction, Laurel (1991) posited that the perception of interactivity existed along a continuum which contained three variables: frequency, range, and significance. Frequency identified how often choices were available; range identified how many choices were available; and significance identified how much the choices really affected the situation. She later added the feeling of participation, indicating how immersed one felt within the experience. Accordingly, a highly interactive experience would be one in which someone had frequent opportunities to make a wide variety of significant choices and in which they felt engaged and immersed within the experience.

In contrast with these two definitions of interaction, it seems that the online learning interaction literature has been so focused on what things are interacting (e.g., learner, instructor, content, computer, environment, etc.) that we have missed the nature of interaction itself. As a result, as researchers and practitioners we have tended to see any of these pairs, which bump up against one another, as evidence of interaction. We thus propose the development of a more nuanced model, one which distinguishes between limited dyadic communication (which we will label transaction) and more qualitatively substantive communication (which we will label interaction). Transaction would be understood as a limited engagement to meet a specific need (or toward a specific purpose) of one of the participants with little intent of ongoing dialog or communication; while interaction reflects an active engagement with the expectation of some level of ongoing communication. Interaction, therefore, goes beyond transaction.

For example, in current parlance, a purely lecture or instructor note-based online course (with no discussion or question and answer dialog, just lectures/ notes and tests) would likely be classified as having a high level of learner-content interaction, a moderate level of learner-instructor interaction, and little to no formal learner-learner interaction. In the proposed new framework, such an educational experience would reflect the presence of learner-instructor transaction and, depending on the student and their approach to the course materials, either learner-content transaction or learner-content interaction. Simply reading the texts would be considered learnercontent transaction, while creating new materials, seeking out additional Web materials and posting content, or reorganizing the materials into a new presentation, would reflect learnercontent interaction. 
Figure 1. Proposed Model of Interaction

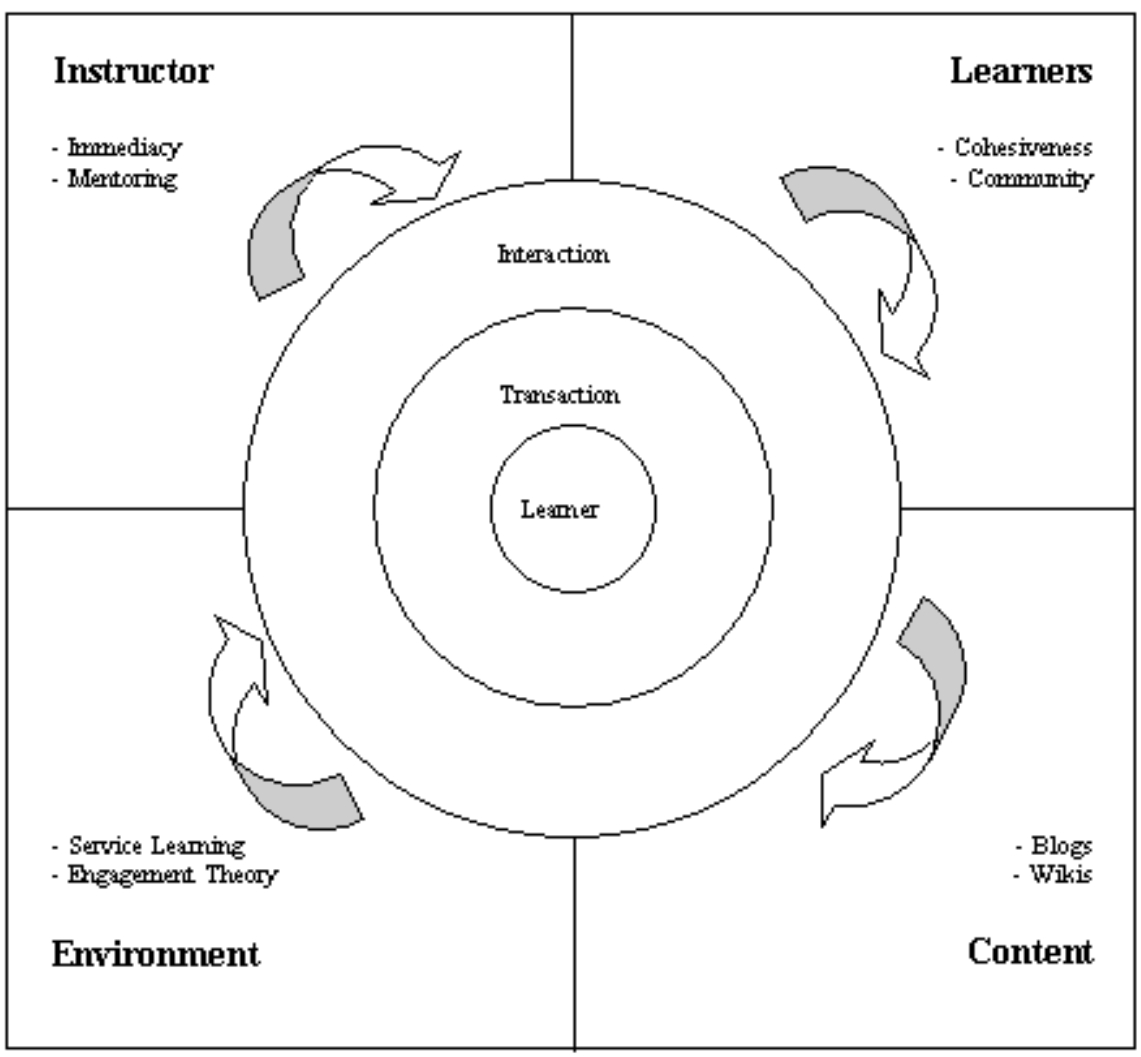

Figure 1. Proposed Model of Interaction

Figure 1 shows this new proposed model of interaction. Essentially, the learner is in the center and has opportunities for four potential realms of engagement: instructor, learners, content, and environment. In each of these realms, the learner can ignore or be deprived of engagement altogether, engage in transactional communication, or engage in fully interactive communication by moving outward from the center of the diagram. On the outer edges of the diagram are a few of results and provocateurs of interaction. Immediacy, therefore, is seen as a benefit of interactive learner-instructor communication, since active ongoing communication is likely to result in an increased feeling of psychological closeness between the learner and instructor. Similarly, the presence of such immediacy is likely to promote increased levels of interaction because learners and instructors are developing a safe and rich interpersonal environment, and this is reflected by the arrow which both comes from and returns to the interaction sphere.

Such a proposed framework goes beyond distinguishing between one-way and two-way communication, and attempts delineate between limited functional communication and rich dyadic and group engagement. Furthermore, this transactive/ interactive framework can be used to address both interpersonal interaction (learner-instructor, learner-learner) within the same framework as non-personal interaction (learner-content, learner-environment), which can otherwise be difficult.

It should be noted that there is nothing inherently wrong in this model with mere transactional communication. We do it frequently when we ask someone the time, watch the evening news, read a journal article, or listen to a recorded lecture. There are even selected social dynamics 
which can result from transactional communication (e.g., para-social dynamics, some perceptions of immediacy); however, the many pedagogical and social benefits presented in online learning best practices generally pre-suppose the movement beyond transaction into interaction.

Admittedly, this is an initial consideration of this new model of online learning interaction. There remains the need for additional research and development to validate this construct. In addition, there is a significant question about whether such a model should consider both positive and negative effects of interactive communication. For example, high levels of learner-learner interaction can produce an educationally rich learning community, or it could also lead toward socially rich, yet intellectually shallow, dialogue and groupthink. Perhaps there should be positive and negative ramifications included in such a robust model of interaction. In addition, there should be additional consideration of how many technologies and dynamics are both the result of and contributor to interaction.

Regardless, there is a need for instructors to distinguish between the mere presence of particular dyadic communication and the presence of genuine interpersonal and contextual interaction as they seek to improve the online educational experience. Furthermore, the development of such a model, corresponding instrumentation, and empirical research, would further the ends of effective online education.

\section{References}

Anderson, J. F. (1979). Teacher immediacy as a predictor of teaching effectiveness. In D. Nimmo (Ed.) Communication Yearbook III (p. 543-559). New Brunswick, NJ.: Transaction Books.

Anderson, T. D. (2003a). Modes of interaction in distance education: Recent developments and research questions. In M. G. Moore and W. G. Anderson (Eds.) Handbook of distance education (p. 129-144). Mahwah, NJ.: Erlbaum.

Anderson, T. D. (2003b). Getting the Mix Right Again: An updated and theoretical rationale for interaction. International Review of Research in Open and Distance Learning, 4(2). Retrieved July 7, 2004 from: http://www.irrodl.org/content/v4.2/anderson.html

Anderson, T. D., and Garrison, D. R. (1998). Learning in a Networked World: New roles and responsibilities. In C. C. Gibson (Ed.) Distance Learners in Higher Education: Institutional responses for quality outcomes (p. 97-112). Madison, WI.: Atwood Publishing.

Andersen, J. F., Andersen, P. A., and Jensen, A. D. (1979). The measurement of immediacy. Journal of Applied Communication Research, 7, 153 - 180.

Arbaugh, J. B. (2000). Virtual classroom characteristics and student satisfaction with Internetbased MBA courses. Journal of Management Education, 24, 32 - 54.

Berge, Z. L. (1997). Characteristics of online teaching in post-secondary, formal education. Educational Technology, 37(3), 35 - 47. 
Blum, K. D. (1999). Gender Differences in Asynchronous Learning in Higher Education: Learning styles, participation barriers and communication patterns. Journal of Asynchronous Learning Networks, 1(3), Retrieved July 7, 2004 from: http://www.aln.org/alnweb/journal/Vol3 issue1/blum.htm

Boettcher, J. V. (1999). Cyber Course Size: Pedagogy and politics. Syllabus, 12(8), 42 - 44.

Brunner, C. (1991). Gender and distance learning. The Annals of the American Academy of Political and Social Science, 514, 133 - 145.

Burnham, E. (1998). Educating Rita at Snow College: The impact of the nontraditional student. ERIC No. ED304185.

Burnham, B. R., and Walden, B. (1997). Interactions in Distance Education: A report from the other side. Paper presented at the 1997 Adult Education Research Conference. Stillwater, Oklahoma. $\quad$ Retrieved $\quad$ May 2004, from: http://www.edst.educ.ubc.ca/aerc/1997/97burnham.html

Carey, J. (1989). Communication as culture. London: Routledge.

Clow, K. E. (1999). Interactive Distance Learning: Impact on student course evaluations, Journal of Marketing Education, 21(2), 97 - 105.

De Verneil, M., and Berge, Z. L. (2000). Going Online: Guidelines for faculty in higher education. International Journal of Educational Telecommunications, 6, 227 - 242.

Everhart, R. (1999). Creating virtual communities, Syllabus, 12(8), 12 - 16.

Gibson, C. C. (1998). The distance learner in context. In C.C. Gibson (Ed.) Distance Learners in Higher Education: Institutional responses for quality outcomes (p. 113-125). Madison, WI.: Atwood Publishing.

Gorham, J. (1988). The relationship between verbal teacher immediacy behaviors and student learning. Communication Education, 37, 40 - 53.

Gunawardena, C. N. (1995) Social presence theory and implications for interaction and collaborative learning in computer conferences. International Journal of Educational Telecommunications, 1, 147 - 166.

Hacker, K. L., and Wignall, D. I. (1997). Issues in predicting user acceptance of computermediated communication in inter-university classroom discussion as an alternative to face-to-face interaction, Communication Reports, 10(1), 108 - 114.

Harasim, L. M. (1989). On-line education: a new domain. In R. Mason and A. Kaye (Eds.) Mindweave: Communication, computers and distance education (p. 50-62). Oxford: Pergamon Press.

Herring, S. C. (2000). Gender differences in CMC: Findings and implications. The CPSR Newsletter, 18(1), $3-11$. 
Hillman, D. C., Willis, D. J., and Gunawardena, C. N. (1994). Learner-Interface Interaction in Distance Education: An extension of contemporary models and strategies for practitioners. The American Journal of Distance Education, 8(2), 30 - 42.

Johnson, D. W., and Johnson, R. T. (1999). Learning Together and Alone: Cooperative, competitive, and individualistic learning (5th ed.). Needham Heights, MA.: Allyn and Bacon.

Kearsley, G. (2000). Online Education: Learning and teaching in cyberspace. Belmont, CA.: Wadsworth/Thomson Learning.

LaRose, R., and Whitten, P. (2000). Re-thinking Instructional Immediacy for Web Courses: A social cognitive exploration. Communication Education, 49, 320 - 338.

Laurel, B. (1991). Computers as theatre. Reading, MA.: Addison Wesley.

Mehrabian, A. (1967). Orientation behaviors and nonverbal attitude communication. Journal of Communication, 17, $324-332$.

Mehrabian, A. (1971). Silent messages. Belmont, CA.: Wadsworth.

Moore, M. G. (1989). Three types of interaction. The American Journal of Distance Education, $3(2), 1-6$.

Moore, M. G., and Kearsley, G. (1996). Distance Education: A systems view. Belmont, CA.: Wadsworth.

Palloff, R. M., and Pratt, K. (1999). Building Learning Communities in Cyberspace: Effective strategies for the online classroom. San Francisco: Jossey-Bass.

Parker, A. (1999), Interactivity in Distance Education: The critical conversation. The Journal of Educational Telecommunications.8, 15 - 30.

Phillips, M. R., and Peters, M. J. (1999). Targeting Rural Students with Distance Learning Courses: A comparative study of determinant attributes and satisfaction levels, Journal of Education for Business, 74(6), 351 - 356.

Rafaeli, S. (1988). Interactivity: From new media to communication. In R. P. Hawkins, J. M. Wiemann and S. Pingree (Eds.) Sage Annual Review of Communication Research: Advancing communication science, Vol. 16 (p. 110-134). Beverly Hills, CA.: Sage.

Roblyer, M. D. (1999). Student motives for taking Internet-based courses at the high school and community college levels. Journal of Research on Computing in Education. 32(1), 157 171.

Rovai, A. P. (2002). Development of an instrument to measure classroom community. The Internet and Higher Education, 5(3), 197 - 211. 
Ryan, A., and Hicks, L. (1997). Social goals, academic goals, and avoiding seeking help in the classroom. Journal of Early Adolescence, 17 (2), 152 - 181.

Saba, F. (1999). Is distance education comparable to "traditional education"? Retrieved September 15, 2000, from: http://www.distance-educator.com/der/comparable.html

Thweatt, K. S., and McCroskey, J. C. (1996). Teacher Nonimmediacy and Misbehavior: Unintentional negative communication. Communication Research Reports, 13(2), 198 204.

Wagner, E. D. (1994). In support of a functional definition of interaction. The American Journal of Distance Education, 8(2), 6 - 29.

Wegerif, R. (1998). The social dimension of asynchronous learning networks. Journal of Asynchronous Learning Networks, 2(1). Retrieved July 7, 2004 from: http://www.aln.org/publications/jaln/v2n1/v2n1_wegerif.asp

Woods, R., and Ebersole, S. (2003). Using non-subject-matter-specific discussion boards to build connectedness in online learning. The American Journal of Distance Education, 17(2), 99 $-118$.

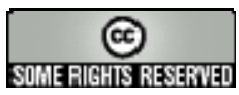

